\title{
RANCANG BANGUN PRESS TOOL UNTUK ALAT BENDING PELAT TIPE DIE-V AIR BENDING
}

\author{
Muhammad Arsyad Suyuti ${ }^{1}$, Rusdi Nur², Muhammad Iswar ${ }^{3}$ \\ 1,2,3 Jurusan Teknik Mesin, Politeknik Negeri Ujung Pandang \\ Jalan Perintis Kemerdekaan Km. 10 Tamalanrea Makassar 90245 Sulawesi Selatan, Indonesia \\ muhammadarsyadsyuti@poliupg.ac.id ${ }^{1}$
}

\begin{abstract}
Abstrak
Pekerjaan pembentukan logam (metal forming) pada industri permesinan maupun pabrikasi las saat ini sangat banyak permintaan khususnya pada pekerjaan yang memerlukan proses bending. Proses bending merupakan pembentukan logam yang umumnya menggunakan lembaran pelat atau batang, baik dari bahan logam ferro maupun logam non ferro dengan cara ditekuk, yang mana dalam proses pembengkokan akan menyebabkan terjadinya pemuluran atau peregangan pada sumbu bidang netral sepanjang daerah bending dan menghasilkan garis bending yang lurus. Penggunaan teknologi tepat guna telah banyak digunakan untuk meningkatkan produktivitas, efisiensi, dan efektivitas dalam proses produksi pada industri permesinan maupun pabrikasi las berskala kecil dan menengah. Salah satu teknologi tepat guna yang memungkinkan diterapkan dalam proses produksi khususnya pekerjaan bending pelat yaitu mesin atau alat press bearing dengan cara menambahkan dengan press tool yang dilengkapi punch dan die penekuk. Press tool adalah salah satu jenis alat bantu pembentukan, pemotongan dan penekukan produk dari bahan dasar lembaran pelat yang operasinya menggunakan mesin press. Melalui penelitian telah tercipta press tool yang dilengkapi komponen pembentuk berupa punch dan die- $\mathrm{V}$ tipe air bending. Adapun spesifikasi press tool ini yaitu: sudut punch sama dengan 850 , radius punch sama dengan 1.5 $\mathrm{mm}$, panjang punch sama dengan $300 \mathrm{~mm}$, sudut die sama dengan $85 \mathrm{o}$, lebar bukaan die sama dengan $33 \mathrm{~mm}$, jarak langkah sama dengan $19 \mathrm{~mm}$.
\end{abstract}

Kata kunci: pembentukan logam, press tool, air bending, punch, die

\section{PENDAHULUAN}

Dewasa ini proses pembentukan logam (metal forming) pada industri permesinan dan bengkel las berkembang sangat pesat khususnya pada proses bending. Proses bending merupakan pembentukan logam yang umumnya menggunakan lembaran pelat atau batang baik dari bahan logam ferro maupun logam non ferro dengan cara ditekuk, dimana pada proses bending ini terjadi pemuluran atau peregangan pada sumbu bidang netral sepanjang daerah bendingan dan menghasilkan garis bending yang lurus. [1]. Fenomena perkembangan pembentukan logam melalui proses bending ini terjadi pada industri pabrikasi permesinan dan bengkel las pada daerah perkotaan sampai pelosok desa baik yang berskala kecil maupun berskala besar. Hal tersebut dipicu oleh semakin banyaknya penggunaan berbagai macam teknologi mekanisasi terutama dalam bidang ketahanan dan keamanan pangan dalam kehidupan masyarakat sehari-hari seperti teknologi proses pasca panen dan teknologiteknologi mekanisasi pertanian lainnya [2].

Jenis pekerjaan bending pelat yang banyak ditemui untuk pembuatan maupun perbaikan pada bengkel pabrikasi permesinan dan las antara lain komponen panel elektronik, panel kendaraan mobil, tool box, pembakaran ikan, alat dan mesin pertanian dan sebagainya [3\&4]. Namun masih banyak bengkel-bengkel yang berskala kecil menekuk pelat dengan cara manual, yaitu menggunakan palu dan landasan besi sebagai alas sehingga waktu yang digunakan tidak efisien dan produk yang dihasilkan pun kurang terjamin kualitasnya. Peralatan yang dimiliki sebuah industri biasanya mesin berkapasitas besar yang mana ongkos operasionalnya pun akan besar, sedangkan untuk memproduksi benda yang berukuran kecil tidak harus menggunakan mesin berkapasitas besar.

Press tool adalah salah satu jenis alat bantu untuk membentuk (forming), memotong (cutting) dan menekuk (bending) benda kerja dari bahan dasar lembaran pelat logam melalui pembentuk punch dan die yang operasinya menggunakan mesin press 
[5\&6]. Pada proses bending pelat terdapat tiga tipe die pembentuk yaitu tipe air bending, wipe die bending dan V-die bending. Dari ketiga tipe tersebut air bending merupakan tipe yang paling umum digunakan untuk menekuk lembaran pelat dari logam karena fleksibilitasnya. Seperti proses bending pada tipe lainnya, penekukan material pelat dengan menggunakan die- $\mathrm{V}$ tipe air bending ini juga dilakukan melalui tekanan punch yang diarahkan ke lembaran pelat logam yang terpasang pada die tersebut[7]. Pada gambar 1. Berikut ini mnunjukkan proses bending dengan menggunakan die $-\mathrm{V}$ tipe air bending:

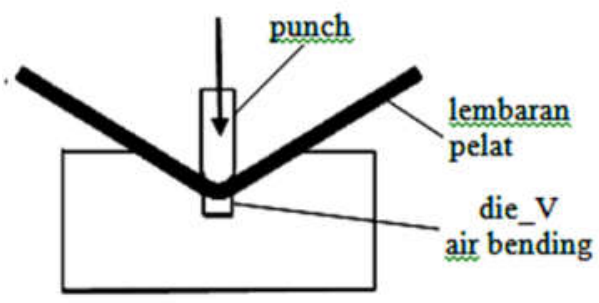

Gambar 1 Illustrasi Die-V Air Bending [8]

Proses pembentukan logam melalui metode air bending dapat menghasilkan sudut bending yang berbeda dari satu pasangan punch dan die pada langkah penekanan yang sama maupun berbeda, dimana sudut bending yang terbentuk oleh tekanan beban yang diberikan (before unloading) dapat berubah menjadi lebih besar setelah tekanan beban dihilangkan (after unloading), fenomena ini yang biasa disebut springback [9]. Gambar 2 berikut ini memperlihatkan illustrasi springback:

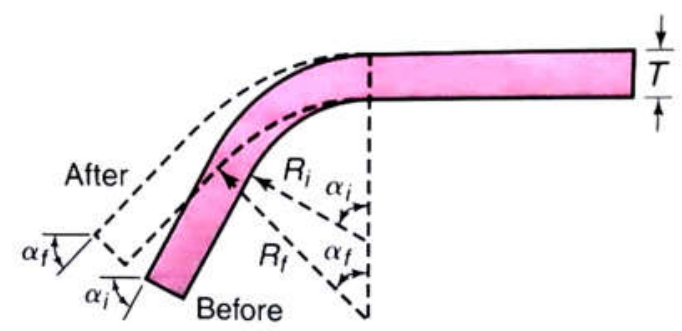

Gambar 2 Illustrasi penomena springback before unloading dan after unloading [8]

Sehingga springback yang terjadi adalah

$=\alpha \mathrm{f}-\alpha \mathrm{i}$

$\alpha f$ - sudut bending after unloading

$\alpha \mathrm{i}$ - sudut bending - benda kerja pada saat rapat pada die (before unloading) .
Ada beberapa parameter yang menentukan besarnya nilai springback pada proses bending yaitu tebal pelat, radius punch, sudut punch, sudut die, radius die, dan clearance punch dan die, kekuatan tarik, modulus elastisitas, kekerasan bahan, lebar bukaan V die dan langkah punch [10\&11]. Sehingga desain yang baik terhadap geometri punch dan die pada pembuatan press tool untuk air bending sangat penting untuk diperhatikan.

Berdasarkan uraian tersebut diatas, permasalahan yang akan diselesaikan ialah bagaimana menciptakan alat bending pelat yang berukuran kecil yang dapat digunakan oleh bengkel permesinan dan pabrikasi las yang berskala kecil dan menengah dengan biaya terjangkau.

Dengan demikian diperlukan penerapan teknologi tepat guna untuk meningkatkan efektifitas pekerjaan proses bending pelat pada industri kecil menengah khususnya pada bengkel permesinan dan pabrikasi las. Penggunaan mesin atau alat teknologi tepat guna telah banyak digunakan untuk meningkatkan produktivitas, efisiensi, dan efektivitas dalam proses produksi pada industri rumah tangga berskala kecil sampai pada daerah pelosok. Salah satu teknologi tepat guna yang memungkinkan diterapkan dalam proses bending pelat logam adalah mesin press yang dilengkapi dengan press tool. Oleh karena itu dilakukan penelitian rancang bangun press tool sebagai alat bending pelat dengan memakai die$\mathrm{V}$ tipe air bending.

\section{METODE PENELITIAN}

Penelitian ini dilaksanakan selama tiga bulan di bengkel mekanik dan laboratorium mekanik Politeknik Negeri Ujung Pandang. Bahan-bahan yang digunakan dalam penelitian ini antara lain besi baja perrnesinan berbentuk poros, persegi dan pelat. Sedangkan peralatan yang digunakan adalah mesin frais, mesin bubut, mesin bor, mesin gerinda, mesin gergaji potong dan berbagai alat ukur dimensi. Tahapan-tahapan rancang bangun press tool tipe air bending ini sebagai berikut:

Pertama yaitu tahap perancangan. Pada tahap perancangan ini terlebih dahulu mendesain konsep press tool yang terdiri dari die set, punch dan die-V. Setelah final konsep rancangan disetujui, selanjutnya dibuat desain gambar sesuai dengan standar ISO. Gambar desain ini meliputi gambar desain rancangan secara keseluruhan dan gambar semua komponen rancangan baik komponen yang dibuat maupun komponen standar.

Kedua yaitu tahapan pembuatan dan perakitan. Pada tahap ini komponen-komponen yang tidak standar dibuat dengan mengacu pada gambar kerja hasil rancangan dan untuk komponen standar 
dibeli. Setelah semua komponen yang dibuat dan dibeli tersedia maka selanjutnya press tool dirakit sesuai dengan final desain.

Dan tahap terakhir yaitu uji coba alat press tool dengan die- $\mathrm{V}$ tipe air bending. Pada tahap ini press tool yang telah dirakit selanjutnya digunakan untuk menekuk pelat dari baja karbon rendah St. 37 ketebalan $3 \mathrm{~mm}$. Eksperimen dilakukan dengan memakai dies sudut 850 . Sedangkan punch yang digunakan bersudut $85^{\circ}$ dan radius $1.5 \mathrm{~mm}$. Setelah eksperimen selesai maka produk hasil tekukan diukur sudut tekuknya menggunakan busur bilah kecermatan 5 o untuk mengetahui sudut bending yang terbentuk.

\section{HASIL DAN PEMBAHASAN}

\section{Hasil Perancangan Press Tool}

Komponen press tool terdiri dari sub rakitan die set, punch dan die. Die set merupakan subrakitan yang berfungsi sebagai tempat untuk memasang komponen punch maupun die. Die set didesain agar dapat berfungsi sebagai alat bantu untuk membengkokkan material pelat dari logam. Die set ini khusus dirancang agar punch dan die yang digunakan dapat diganti-ganti sesuai dengan kebutuhan. Setelah punch dan die dirakit pada die set maka alat bantu tersebut disebut press tool. Adapun beberapa komponen telah didesain dalam rancang bangun press tool ini antara lain:

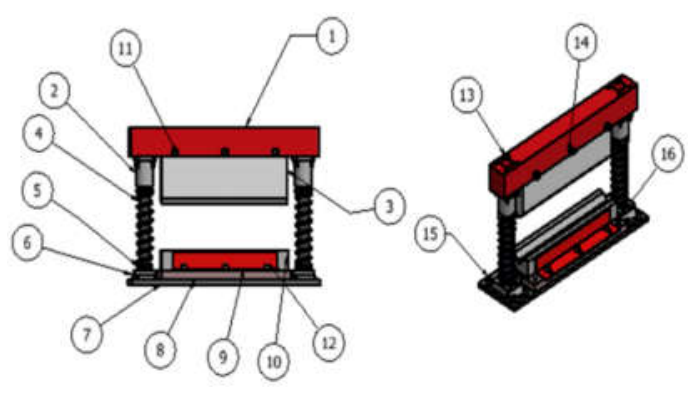

\section{Gambar 3 Konstruksi Rancangan Press Tool}

Berdasarkan gambar 1. diatas, press tool memiliki beberapa komponen yaitu sebagai berikut: 1) Top plate; 2) Bearing; 3) Punch; 4) Pegas; 5) Guide post; 6) Dudukan guide post; 7) Bottom plate; 8) Pelat pelapis; 9) Pelat pengunci die; 10) Die; 11) Baut pengikat punch dan Top plate; 12) Baut pengunci die; 13) Baut bearing; 14) Mur pengikat punch dan top plate; 15)Baut dudukan; 16) Baut pelapis die.

Terdapat beberapa komponen memiliki peran penting pada press tool untuk alat bending $V$ Brake ini. Salah satu komponen yang kritis yang membutuhkan desain yang tepat adalah pegas tekan. Dengan demikian diperlukan pemilihan pegas tekan yang akan digunakan sebagai berikut ini:

1. Massa komponen yang membebani pegas tekan

Komponen press tool yang membebani pegas tekan yaitu pelat atas (top plate), punch, ring, dan bearing. Untuk menentukan massa komponenkomponen tersebut dapat dihitung dengan menggunakan persamaan sebagai berikut [12]:

$$
\mathrm{W}=\mathrm{V} \cdot \rho
$$

Dimana: $\mathrm{W}=$ massa komponen $(\mathrm{kg}) ; \mathrm{V}=$ volume komponen $\left(\mathrm{mm}^{3}\right) ; \rho=$ massa jenis $\left(\mathrm{kg} / \mathrm{mm}^{3}\right)$. Komponen-komponen press tool tersebut terbuat dari baja karbon sehingga massa jenisnya sebesar 7860 $\mathrm{kg} / \mathrm{m}^{3}=0.00000786 \mathrm{~kg} / \mathrm{mm}^{3}$. Berikut adalah perhitungan massa komponen-komponen yang membebani pegas:

a. Top plate
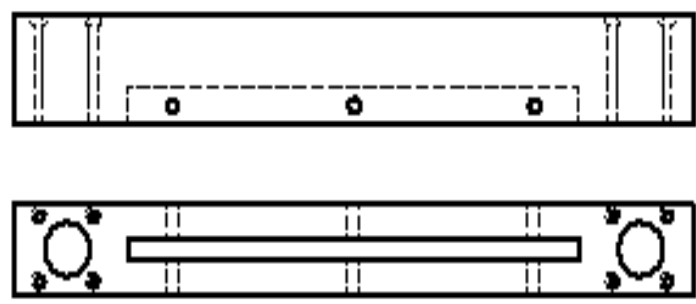

Gambar 4 Desain top plate

Berdasarkan dimensi desain top plate maka massa top plate dapat dihitung sebagai berikut:

volume top plate $\left(\mathrm{V}_{\mathrm{I}}\right)=\mathrm{p} \times 1 \times \mathrm{t}$

volume lubang poros $\left(\mathrm{V}_{\mathrm{II}}\right)=\pi \mathrm{r}^{2} \mathrm{t}$

volume alur punch $\left(\mathrm{V}_{\mathrm{III}}\right)=\mathrm{p} \times 1 \times \mathrm{t}$

volume lubang baut $\left(\mathrm{V}_{\mathrm{IV}}\right)=\pi \mathrm{r}^{2} \mathrm{t}$

dimana :

$\mathrm{p}=$ panjang $(\mathrm{mm}), \mathrm{l}=$ lebar $(\mathrm{mm}), \mathrm{t}=$ tebal $(\mathrm{mm})$

dan $\mathrm{r}=$ jari-jari $(\mathrm{mm})$.

sehingga volume total

$\left(\mathrm{V}_{\text {tot }}\right)=\mathrm{V}_{\mathrm{I}}-\left(\mathrm{V}_{\mathrm{II}}+\mathrm{V}_{\mathrm{III}}+\mathrm{V}_{\mathrm{IV}}\right)$

$\mathrm{V}_{\text {tot }}=1.408 .960,8 \mathrm{~mm}^{3}$

Maka massa top plate

$\left(\mathrm{W}_{\text {top plate }}\right)=\mathrm{V} \times \rho$

$=11,408 \mathrm{~kg}$

b. Punch

Punch merupakan komponen yang berfungsi sebagai penekan sekaligus pembentuk lembaran 
pelat pada saat proses bending terjadi. Material punch yaitu baja karbon dikeraskan hingga 55 HRC. Berikut ini gambar punch yang telah didesain:

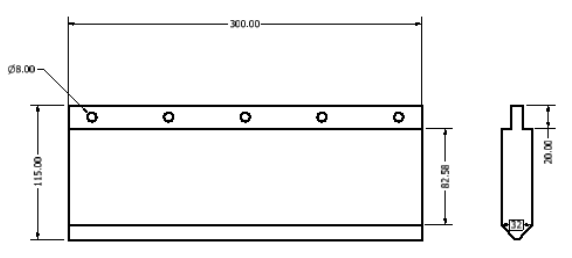

Gambar 5 Desain Punch

Berdasarkan dimensi desain punch, maka berat punch dapat dihitung sebagai berikut:

volume persegi $\left(\mathrm{V}_{\mathrm{I}}\right)=\mathrm{p} \times 1 \times \mathrm{t}=1.104 .000 \mathrm{~mm}^{3}$

volume lingkaan $\left(V_{\text {II }}\right)=\pi r^{2} t=4.823 \mathrm{~mm}^{3}$

volume persegi $\mathrm{V}_{\mathrm{III}}=\mathrm{p} \times 1 \times \mathrm{t}=792.768 \mathrm{~mm}^{3}$

volume segitiga $V_{I V}=L_{a} \times t=59.616 \mathrm{~mm}^{3}$

sehingga volume total

$\left(\mathrm{V}_{\text {tot }}\right)=\mathrm{V}_{\mathrm{I}}-\mathrm{V}_{\mathrm{II}}+\mathrm{V}_{\mathrm{III}}+\mathrm{V}_{\mathrm{IV}}$

$=1.951 .560,96 \mathrm{~mm}^{3}$.

Maka massa punch

$\left(\mathrm{W}_{\text {punch }}\right)=15,339 \mathrm{~kg}$.

c. Bearing

Dalam desain bearing yang digunakan adalah bearing standar dan tersedia dipasaran. Bearing ini berfungsi sebagai busing agar tidak terjadi gesekan antara top pelat dan guide post:

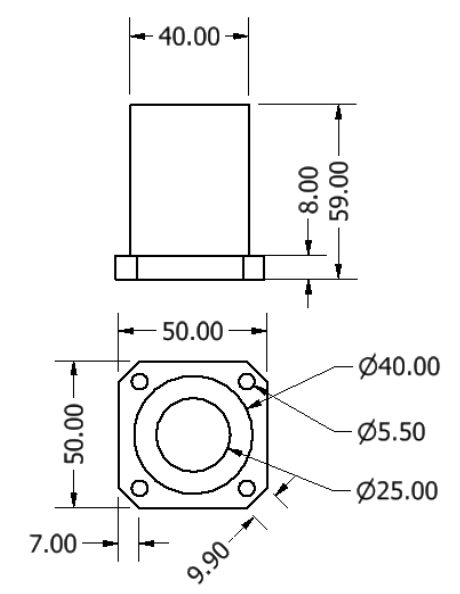

Gambar 6 Bearing

Suyuti, Muhammad Arsyad., dkk; Rancang Bangun Press Tool Untuk Alat Bending Pelat Tipe Die-V Air Bending
Untuk massa jenis bahan stainles steel adalah $7480 \mathrm{~kg} / \mathrm{m}^{3}$, maka beban bearing

$\left(\mathrm{W}_{\text {bearing }}\right)=2,3770324 \mathrm{~kg}$.

d. Ring

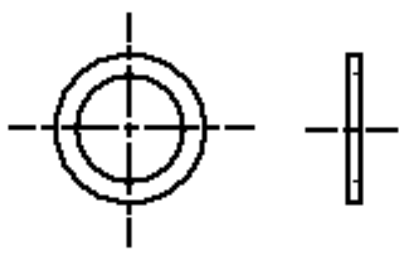

Gambar 7 Ring

Diameter luar ring $40 \mathrm{~mm}$, diameter dalam $30 \mathrm{~mm}$, maka untuk massa jenis bahan kuningan adalah $8400 \mathrm{~kg} / \mathrm{m}^{3}$ atau $0.0000084 \mathrm{~kg} / \mathrm{mm}^{3}$ maka

$\mathrm{W}_{\text {ring }}=0.046 \mathrm{~kg}$.

e. Total beban yang diterima pegas

Dari perhitungan beban komponen-komponen tersebut ditas maka total beban yang diterima oleh pegas adalah:

$$
\begin{aligned}
& \mathrm{W}_{\text {total }}=\mathrm{W}_{\text {top plate }}+\mathrm{W}_{\text {punch }}+\mathrm{W}_{\text {bearing }}+\mathrm{W}_{\text {ring }} \\
& =29,170 \mathrm{~kg}
\end{aligned}
$$

2. Kekuatan beban oleh pegas

Agar pegas yang dipilih dapat mengembalikan pelat atas (top plate), punch, ring dan bearing pada posisi semula setelah pembebanan proses bending berakhir, maka diperlukan perhitungan kekuatan pegas yang akan digunakan. Adapun parameter-parameter pegas yang dipilih dalam desain yaitu: diameter pegas $(\mathrm{D})=40 \mathrm{~mm}$, diameter kawat $(\mathrm{d})=5 \mathrm{~mm}$ dan modulus geser $(\mathrm{G})=$ $83 \times 10^{3} \mathrm{~N} / \mathrm{mm}$. Maka pada perhitungan persamaan yang digunakan adalah sebagai berikut [12 \& 13]:

$$
\begin{aligned}
& W=\frac{\delta \cdot G \cdot d^{4}}{8 \cdot D^{3} \cdot n} \\
& \mathrm{~W}=\text { beban aksial dari pegas }(\mathrm{kg}) \\
& \delta=\text { defleksi pegas ( } \mathrm{mm}) \\
& \mathrm{G}=\text { modulus kekakuan }(\mathrm{N} / \mathrm{mm}) \\
& \mathrm{d}=\text { diameter kawat }(\mathrm{mm}) \\
& \mathrm{D}=\text { diameter pegas }(\mathrm{mm}) \\
& \mathrm{n}=\text { jumlah koil aktif }
\end{aligned}
$$




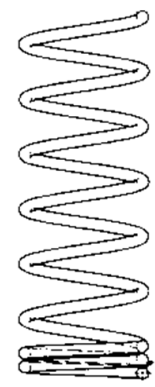

\section{Gambar 8 Pegas}

Berdasarkan gambar di atas, maka dalam menentukan besar beban aksial dari pegas dapat dihitung seperti berikut ini:

$$
\begin{gathered}
W=\frac{\delta \cdot G \cdot d^{4}}{8 \cdot D^{3} \cdot n}=\frac{(L o-L i) \cdot G \cdot d^{4}}{8 \cdot D^{3} \cdot n} \\
W=\frac{(110-100) \cdot 83 \times 10^{3} \cdot 5^{4}}{8 \cdot 40^{3} \cdot 2} \\
=506,592 \mathrm{~N}
\end{gathered}
$$

Dari hasil perhitungan teoritis di atas diperoleh besar beban aksial dari kedua pegas yang digunakan sama dengan 506,592 N.

Sehingga berdasarkan hasil perhitungan total beban komponen die set yang diterima oleh pegas (Wtot) sebesar 29,17 kg atau 263,820 $\mathrm{N}$ maka pegas yang digunakan aman karena beban pegas $(506,592 \mathrm{~N})>$ total beban yang diterima pegas $(263,820 \mathrm{~N})$.

\section{Desain Die Tipe Air Bending}

Gambar 9 berikut ini memperlihatkan final desain Die Tipe Air Bending. Die terbuat dari baja karbon tinggi dikeraskan hingga 55 HRC. Sedangkan ukurannya $300 \mathrm{~mm} \times 60 \mathrm{~mm} \times 60 \mathrm{~mm}$ dan sudut die $=85^{\circ}$.
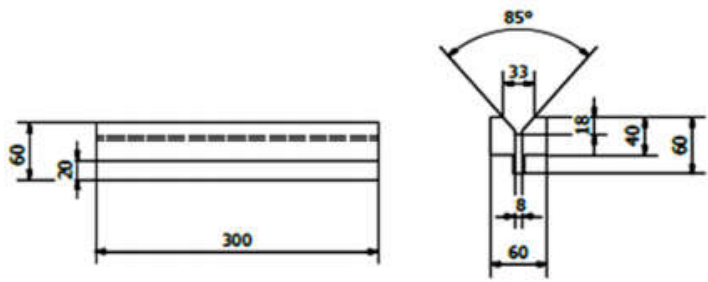

\section{Gambar 9 Desain Die Tipe Air Bending}

Setelah final desain press tool selesai maka tahap selanjutnya yaitu membuat press tool berupa satu unit die set yang dilengkap dengan masingmasing satu buah punch dan die. Sudut punch $=85^{\circ}$, radius punch $=1,5 \mathrm{~mm}$, sudut die (tipe air bending) $=$ $85^{\circ}$ dan panjang punch/die (garis bending) $=30 \mathrm{~mm}$. Press tool ini mampu membending komponen produk dari berbagai jenis lembaran material dari logam secara presisi. Adapun press tool hasil rancang bangun dapat dilihat pada gambar 9 berikut ini:

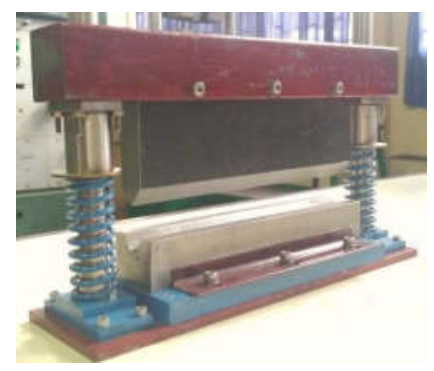

\section{Gambar 10 Hasil Rancang Bangun Press Tool Air Bending V Brake}

\section{Hasil Pengujian Press Tool Air Bending V Brake}

Setelah tahap proses perakitan selesai, dilakukan uji fungsi dari press tool. Sudut die-V air bending yang dipakai sama dengan $85^{\circ}$. Pada proses pengujian alat bending ini sudut yang ingin dicapai yaitu $90^{\circ}$. Langkah penekanan diberikan sampai benda kerja rapat pada permukaan die sampai terbentuk sudut bending ( $\alpha \mathrm{i})$ sebesar $85^{\circ}$ (before unloading). Sistem pengujian press tool dapat dilihat pada gambar 11 berikut.

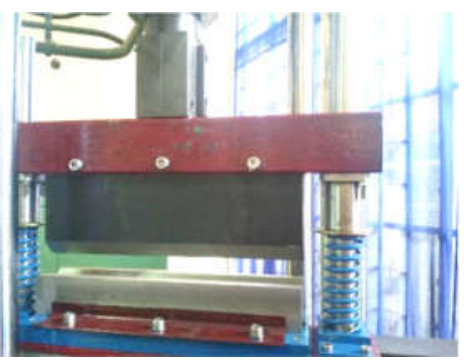

\section{Gambar 11 Press Tool terpasang pada Universal Testing Machine (UTM)}

Gambar 12 berikut ini menunjukkan hasil proses bending pelat menggunakan press tool yang terpasang pada mesin UTM. Material benda kerja yaitu baja karbon St.37 dengan dimensi 300 mm x 60 $\mathrm{mm} \times 3 \mathrm{~mm}$. 

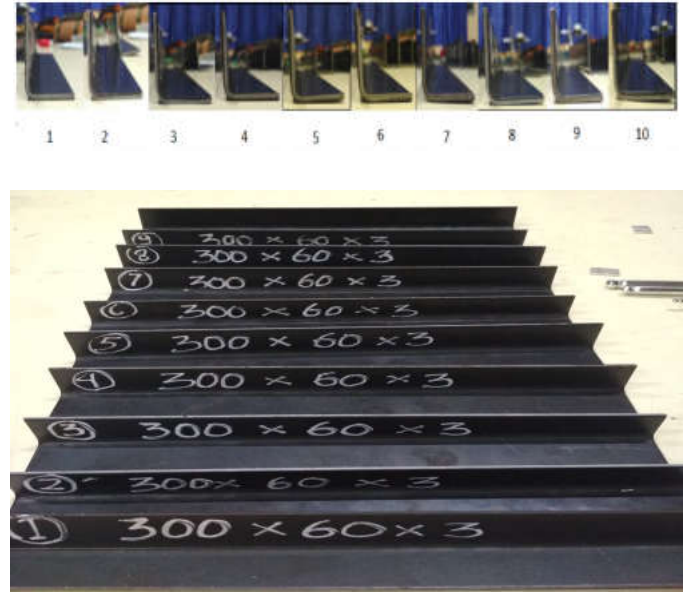

\section{Gambar 12 Produk hasil uji coba}

Setelah proses bending selesai maka sudut bending ( $\alpha \mathrm{f})$ after unloading benda kerja diukur menggunakan alat ukur busur bilah kecermatan 5 menit. Adapun hasil pengukuran tersebut dapat dilihat pada tabel 1 berikut:

Tabel 1 Data Sudut Bending Benda Kerja Yang Dibentuk Pada Press Tool.

\begin{tabular}{llllll}
\hline \multirow{2}{*}{ No } & \multirow{2}{*}{$\begin{array}{l}\text { Beban } \\
(\mathrm{N})\end{array}$} & \multicolumn{3}{l}{ Sudut Bending } & Springback \\
\cline { 3 - 5 }$\left({ }^{0}\right)$ & $(")$ & $\left({ }^{0}\right)$ & $\left({ }^{o}\right)$ \\
\hline 1 & 395 & 90 & 15 & 90,25 & 5,25 \\
\hline 2 & 349 & 90 & 25 & 90,42 & 5,42 \\
\hline 3 & 345 & 90 & 30 & 90,5 & 5,5 \\
\hline 4 & 349 & 91 & 0 & 91 & 6 \\
\hline 5 & 342 & 89 & 30 & 89,5 & 4,5 \\
\hline 6 & 342 & 91 & 0 & 91 & 6 \\
\hline 7 & 349 & 90 & 45 & 90,75 & 5,75 \\
\hline 8 & 355 & 90 & 0 & 90 & 5 \\
\hline 9 & 343 & 90 & 5 & 90,08 & 5,08 \\
\hline 10 & 345 & 90 & 15 & 90,15 & 5,15 \\
\hline
\end{tabular}

Berdasarkan tabel 1 di atas menunjukkan bahwa sudut bending hasil penekukan press tool dengan die-V tipe air bending $85^{\circ}$ diperoleh springback yang terjadi antara $4,50^{\circ}$ s.d $6,00^{\circ}$, sehingga sudut bending yang terbentuk antara $89,50^{\circ}$ s.d $91,00^{\circ}$. Dengan demikian penyimpangan sudut yang terjadi antara $-0,5^{\circ} \mathrm{s} . \mathrm{d} 1,00^{\circ}$. Springback yang menghasilkan sudut bending tepat $90^{\circ}$ diperoleh pada hasil bending nomor 8 sebesar $5,00^{\circ}$. Sedangkan springback yang paling besar sama dengan $6^{\circ}$ sehingga sudut bending yang terbentuk sama dengan $91^{\circ}$ terletak pada proses bending nomor 4 dan 6 . Hasil proses bending yang diperoleh ditinjua dari segi springback dan sudut bending yang terbentuk menunjukkan bahwa hasil proses bending memiliki kualitas yang baik dan dapat pakai pada konstruksi permesinan umum yang terdapat pada bengkel pabrikasi permesinan dan pengelasan.

\section{KESIMPULAN}

Berdasarkan hasil penelitian dapat disimpulkan bahwa:

1. Hasil rancang bangun press tool dengan die-V tipe air bending dapat berfungsi sebagai alat bantu produksi untuk proses bending pelat logam pada pekerjaan konstruksi umum.

2. Spesifikasi press tool yang diciptakan yaitu: Die$\mathrm{V}$ tipe air bending, sudut punch sama dengan $85^{\circ}$, radius punch sama dengan $1.5 \mathrm{~mm}$, panjang punch sama dengan $300 \mathrm{~mm}$, sudut die sama dengan $85^{\circ}$, lebar bukaan die sama dengan 33 $\mathrm{mm}$, jarak langkah bebas sama dengan $19 \mathrm{~mm}$.

3. Hasil uji coba press tool dalam menekuk material pelat baja St.37, dengan menggunakan langkah punch maksimum $19 \mathrm{~mm}$ diperoleh sudut bending pelat yang terbentuk sama dengan $89,50^{\circ}$ s.d $91,00^{\circ}$.

Adapun saran untuk pengembangan penelitian ini:

1. Perlu dilakukan penelitian lebih lanjut untuk material yang lainnya seperti baja karbon sedang, baja karbon tinggi, stainless steel dan lain-lain.

2. Perlu dilakukan pengembangan penelitian terhadap parameter punch dan die untuk mendapatkan kualitas hasil proses bending yang lebih optimal.

\section{UCAPAN TERIMA KASIH}

Melalui artikel jurnal ini penulis dengan tulus mengucapkan terima kasih kepada: 1). Kemenristekdikti atas dana desentralisasi program penelitian dan pengabdian masyarakat tahun 2019 yang telah diberikan. 2). Direktur dan Ketua UPPM Politeknik Negeri Ujung Pandang yang memberikan kesempatan untuk mengikuti program Penelitian Terapan Unggulan Perguruan Tinggi ini. 3) Semua pihak yang terlibat dalam penelitian ini.

Semoga hasil penelitian ini dapat memenuhi tujuan yang diharapkan dan dirasakan manfaatnya oleh masyarakat, khususnya bagi industri yang banyak melakukan proses pabrikasi untuk pembentukan logam (metal forming) khususnya proses bending. Akhirnya kepada Allah-lah kami serahkan semuanya, semoga segala aktivitas kita dinilai-Nya sebagai ibadah dan mendapatkan amal jariah dari-Nya. Amin !!!. 


\section{DAFTAR PUSTAKA}

[1] Suyuti MA, Iswar M, Nur R. Effect of Punch Parameters on Springback for Mild Carbon Steel in A V-Shape Bending Process. InIOP Conference Series: Materials Science and Engineering 2019 Jun (Vol. 541, No. 1, p. 012015). IOP Publishing.

[2] Suyuti MA. Rancang Bangun Prototipe Alat Metal Forming Sirip Roda Besi Traktor Tangan. Jurnal Sinergi Jurusan Teknik Mesin. 2019 May 25;13(1):62-74.

[3] Suyuti MA, Nur R. The Influence of Punch Angle on the Spring Back during V-Bending of Medium Carbon Steel. InAdvanced Materials Research 2015 (Vol. 1125, pp. 157-160). Trans Tech Publications.

[4] Suyuti MA, Nur R, Iswar M. Springback Hasil Proses Tekuk Bentuk "V" Pelat Baja Karbon St. 60. Ketebalan $4 \mathrm{~mm}$. InSeminar Nasional Hasil Penelitian \& Pengabdian Kepada Masyarakat (SNP2M) 2018 Dec 30

[5] Gautama P, Ka'ka S, Suyuti MA, Susanto TA. Desain Prototipe Alat Press Tool untuk Pembuatan O-Ring Sistem Pneumatik. Jurnal Sinergi Jurusan Teknik Mesin. 2019 May 25;12(2):114-23.

[6] Suyuti MA. Rancang Bangun Simpel Press Tool untuk Bending V Bottoming. Jurnal Sinergi
Jurusan Teknik Mesin. 2019 May 26;13(2):16073.

[7] Gupta TR, Payal HS. Effect of Die and Punch Geometry on Spring Back in Air Bending of Electrogalvanized CR4 Steel. International Journal of Applied Engineering Research. 2017;12(11):2792-7.

[8] Suyuti MA, Nur R, Iswar M. Perancangan Alat Proses Tekuk (Teori Dan Aplikasi). Deepublish; 2019 Oct 1.

[9] Kazan R, Firat M, Tiryaki AE. Prediction of springback in wipe-bending process of sheet metal using neural network. Materials \& design. 2009 Feb 1;30(2):418-23.

[10]Kumar A, Viswanath P, Mahesh K, Swati M, Kumar PM, Abhijit A, Singh S. Prediction of springback in V-bending and design of dies using finite element simulation. International Journal of Materials and Product Technology. 2010 Jan 1;39(3-4):291-301.

[11]Buang MS, Abdullah SA, Saedon J. Effect of die and punch radius on springback of stainless steel sheet metal in the air v-die bending process. Journal of Mechanical Engineering and Sciences. 2015 Jun;8:1322-31

[12]Nur R, Suyuti MA. Perancangan mesin-mesin industri. Deepublish; 2018 Jan 16.

[13]Dahlan D. Elemen mesin. Jakarta: Harta Prima. 2012. 